\title{
Alkanols for the Extraction of Vanadium (V) From Hydrochloric Acid Solutions
}

\author{
James O. Ojo ${ }^{1} \&$ David A. Oyegoke ${ }^{1}$ \\ ${ }^{1}$ Department of Chemistry, Federal University of Technology, Akure, Ondo State, Nigeria \\ Correspondence: James O. Ojo, Department of Chemistry, Federal University of Technology, P.M.B. 704, Akure, \\ Ondo State, Nigeria. Tel: 234-803-811-1797. E-mail: oluwasanjo85@yahoo.com
}

Received: May 20, 2013 Accepted: July 15, 2013 Online Published: July 30, 2013

doi:10.5539/ijc.v5n3p123 URL: http://dx.doi.org/10.5539/ijc.v5n3p123

\begin{abstract}
Extractive recovery of vanadium (V) from hydrochloric acid solutions using alkanols (1-butanol and 1-octanol) dissolved in $\mathrm{n}$-heptane has been investigated by liquid-liquid extraction, propelled by the need to proffering alternatives to the scarce and relatively costly organophosphorous extractants. At the studied $\mathrm{pH}$ range (1.0-4.0), with 1- butanol as extractant, the percentage $\mathrm{V}(\mathrm{V})$ extraction (extraction efficiency, $\mathrm{E} \%$ ) reached optimum $(\mathrm{E} \%=$ 63.3 ) at $\mathrm{pH}$ of 0.5 , and for 1-octanol, optimum $\mathrm{E} \%$ was 73.3 at $\mathrm{pH} 1.0$.Increasing concentration of $\mathrm{HCl}$ at the studied range (1.0-6.0 $\left.\mathrm{mol} \mathrm{L}^{-1}\right)$ was found to have an appreciable effect on percentage $\mathrm{V}(\mathrm{V})$ extraction. With both extractants, $\mathrm{E} \%$ peaked at $6.0 \mathrm{~mol} \mathrm{~L}^{-1} \mathrm{HCl}$ with values 86.7 and $70.0 \%$ for 1-butanol and 1-octanol, respectively. With increase in the concentration of extractants, both extractants produced a trend of increase/decrease in $\mathrm{E} \%$ for $\mathrm{V}(\mathrm{V})$, suggesting the extraction of two different species. The optimal percentage extraction values were 76.7 and $96.7 \%$ observed at $\log [1$-butanol $]=0.81 \mathrm{~mol} \mathrm{~L}^{-1}$ and $\log [1$-octanol $]=0.49 \mathrm{~mol} \mathrm{~L}^{-1}$, in that order. The determined enthalpy change, $\Delta \mathrm{H}$, for 1-butanol and 1-octanol systems were $-19.9 \mathrm{~kJ} \mathrm{~mol}^{-1}$ and $-37.1 \mathrm{~kJ} \mathrm{~mol}^{-1}$, respectively, indicating exothermic extraction processes. On the number of required extraction stages, 1-octanol gave a higher extraction efficiency after three consecutive extractions $(\mathrm{E} \%=99.3)$ than 1-butanol $(\mathrm{E} \%=88.6)$. Recycling experiment showed 1-octanol as more recyclable than 1-butanol (Recycling coefficient R.C. $=1.0$ for 1-octanol while R.C. $<1.0$ for 1-butanol). All extractants mixed with 1-butanol were found antagonistic. All added foreign ions decreased $\mathrm{E} \%$ for $\mathrm{V}(\mathrm{V})$. From slope analysis, analytical and spectra data, the extracted complexes have been formulated as $\mathrm{VO}_{2} \mathrm{Cl} \cdot \mathrm{nROH}$ and $\left(\mathrm{VO}_{2} \mathrm{Cl}\right)_{\mathrm{m}} \cdot \mathrm{nROH}$ (where $\mathrm{m}>\mathrm{n}$ ) at low and high concentrations of extractant, respectively. On the whole, 1 -octanol could be adjudged a better extractant for vanadium (V) under the prevailing experimental conditions.
\end{abstract}

Keywords: vanadium (V), extraction, hydrochloric acid, alkanol, recycling, slope analysis, spectra

\section{Introduction}

With the applications of vanadium in various areas of human endeavours such as heat and corrosion-resistant super-alloys, aerospace materials, catalysts e.t.c. the trials of varied extractants for the solvent extraction of vanadium from its depleted primary sources will continually witness an upsurge. Interestingly, the alkanols fall under this category of extractants currently generating waves of interest. Before the current trend, studies involving the use of solvating organophosphorous compounds for $\mathrm{V}(\mathrm{V})$ extraction with varied efficiencies have been reported (Alibrahim, Shlewit, \& Alike, 2008; Ojo, 2010). For instance, V(V) has been extracted and separated from associated metal ions from $5.0 \mathrm{~mol} \mathrm{~L}^{-1} \mathrm{HCl}$ solution with tri-n-butyl phosphate (TBP) dissolved in kerosene (Thomas et al. 2003). Closely related, was the optimal and appreciable extraction of $\mathrm{V}(\mathrm{V})$ as $\mathrm{VO}_{2} \mathrm{Cl}$ from $6.0 \mathrm{~mol} \mathrm{~L}^{-1} \mathrm{HCl}$ by TBP dissolved in n-hexane reported by the current author (Ojo, Ipinmoroti, \& Adeeyinwo, 2007).

In contrast were the observations made on $\mathrm{V}(\mathrm{V})$ extraction from diluted and concentrated $\mathrm{HNO}_{3}$ solutions where the extraction efficiencies were very low $(\mathrm{Ojo}, 2010)$. As a follow up to the $\mathrm{V}(\mathrm{V}) / \mathrm{HCl} / \mathrm{TBP} / \mathrm{n}$-hexane extraction study, the author separated $\mathrm{V}(\mathrm{V})$ and $\mathrm{Mo}(\mathrm{VI})$ from concentrated $\mathrm{HCl}$ solutions by co-extracting them using TBP, followed by selective stripping with a remarkable success (Ojo, 2013). The demerit of the TBP/HCl system remains the observed high degradation of TBP at high concentration of $\mathrm{HCl}$, rendering recycling prospects diminutive, and besides TBP is relatively costly.

Concerning the acidic extractants, a wide range of them have been utilized for the extractive recovery of vanadium 
(V), with their exchangeable protons replaced by cationic V(V) species (Jain, Mandalia, \& Suresh, 2008; Jain \& Mandalia, 2009).

On the use of amines as extractants for $\mathrm{V}(\mathrm{V})$, a host of successful extractions in alkaline media involving anionic vanadium (V) species have been carried out (El-Nadi, Awwad, \& Nayl, 2009; Bal et al., 2004).

As regards the alkanols, the high molecular weight members such as octanol, quite lipophillic, have recorded tremendous success as reagents/solvents in the extraction of many valuable metals. Octan-1-ol has been used to quantitatively extract $\mathrm{Nb}(\mathrm{V})$ and $\mathrm{Ta}(\mathrm{V})$ from sulphate leach liquor (El-Hazek et al., 2012). Some workers have also reported the extraction of $\mathrm{Al}(\mathrm{III}), \mathrm{Ga}$ (III) and In(III) from perchlorate solutions by I-octanol/octane solvent system (Yamada et al., 2006). Tantalum (V) and niobium (V) have equally been separated from $\mathrm{HF} / \mathrm{H}_{2} \mathrm{SO}_{4}$ mixture by sec-octanol with remarkable high efficiencies and notably high recycling potential implying that the extractant is rarely degraded (Huifang, Wannian, \& Yugi, 1996).

From the review of literature, it is obvious that the alkanols investigated by previous workers are rarely degraded in the dissolution media, which is a plus to their recycling potential and cost-effectiveness in contrast to TBP, these, in addition to the rarely reported $\mathrm{V}(\mathrm{V})$-alkanol extraction inevitably make the current study a worthwhile effort.

\section{Materials and Methods}

\subsection{Materials Used and Their Sources}


$\mathrm{As}_{2} \mathrm{O}_{3}$, and the reagents n-butanol, n-octanol, n-decanol, n-pentanol, isopentyl alcohol, trioctylamine (TOA), tri-n-butyl phosphate (TBP) and di (2-ethylhexyl) phosphoric acid (D2EHPA) were purchased from the British Drug House Limited (BDH). All the materials were of analytical grade except the reagents (solvents) and were used without further purification.

Ammonium metavanadate $(3.51 \mathrm{~g}, 0.03 \mathrm{~mol})$ was dissolved in various concentrations of hydrochloric acid with $\mathrm{KCl}(7.48 \mathrm{~g}, 0.01 \mathrm{~mol})$ added (to maintain a fairly constant ionic strength) and finally made up to the 1-litre mark as $\mathrm{V}(\mathrm{V})$ stock solution.

Different concentrations of 1-butanol and 1-octanol in the ranges $6.52-10.89 \mathrm{~mol} \mathrm{~L}^{-1}$ and $1.85-4.32 \mathrm{~mol} \mathrm{~L}^{-1}$, respectively, were prepared by dissolving appropriate volumes of the pure alkanols in $\mathrm{n}$-heptanes and made up to the 1-litre mark with the diluent.

\subsection{Extraction and Analytical Procedure}

Portions of $15 \mathrm{~mL}$ of $\mathrm{V}(\mathrm{V})$ solutions were transferred with portions of $15 \mathrm{~mL}$ of 1-butanol or 1-octanol (or their mixtures) into a $250 \mathrm{~mL}$ separating funnel, and shaken with a mechanical shaker at $120 \mathrm{rpm}$ for 5 mins (found optimum from preliminary studies) at a temperature of $301 \mathrm{~K}$ (prior to establishing optimal temperature).

In each case, the phases were allowed to settle, disengaged and separated, and the lower aqueous layer was run out through the tap while the organic layer was poured out through the top to avoid contamination. The effects of $\mathrm{pH}$, acid $(\mathrm{HCl})$ and extractant concentrations, temperature, mixed extractants, extraction stages, recycling of extractants and foreign ions were studied by varying the one under investigation while keeping the others constant as follows: $\mathrm{pH}$ varied in the range $0.5-4.0$ with added few drops of concentrated $\mathrm{NaOH}$ or $\mathrm{HCl}$ to the $\mathrm{V}(\mathrm{V})$ aqueous portions with effort made to minimize much changes in volume, and subsequently measured by the $\mathrm{pH}$ meter, LABEX LDA 861 model. Each of the portions was extracted with equal volume of 1-butanol or 1-octanol (or their mixtures) as the case may be; concentration of $\mathrm{HCl}$ varied in the range 1.0-7.0 mol L-1 followed by dissolution of the appropriate amounts of $\mathrm{NH}_{4} \mathrm{VO}_{3}$ in the different concentrations of $\mathrm{HCl}$ and finally made up to the 1-litre mark; temperature was varied between 301 and $321 \mathrm{~K}$ by heating separately the aqueous and organic portions on a hot plate to the desired temperature measured with a thermometer, mixed and finally shaken; mixed extractants, different extractants at a concentration of $10 \%(\mathrm{v} / \mathrm{v})$ were separately mixed with 1-butanol and 1-octanol at their established optimal concentrations of $7.61 \mathrm{~mol} \mathrm{~L}^{-1}(70 \% \mathrm{v} / \mathrm{v})$ and $3.09 \mathrm{~mol} \mathrm{~L}^{-1}(50 \% \mathrm{v} / \mathrm{v})$, respectively, and made up to the appropriate volume with n-heptane, and subsequently equilibrated with a constant volume of $V(V)$ solution; extraction stages was carried out by repeatedly extracting a portion of $15 \mathrm{~mL}$ of the $\mathrm{V}(\mathrm{V})$ aqueous stock solution with equal volumes of fresh alkanol extractant; recycling study was investigated by repeatedly using the stripped alkanols to extract fresh portions of the $\mathrm{V}(\mathrm{V})$ aqueous solution; and foreign ions was by introducing 0.0015 and $0.003 \mathrm{~mol} \mathrm{~L}^{-1}$ foreign ions in form of their compounds into the $\mathrm{V}(\mathrm{V})$ stock solutions, followed by extraction.

The amount of vanadium extracted was determined by UV-visible spectrophotometry of the yellow phosphotungstate-vanadium complex at $400 \mathrm{~nm}$. 
The sample $(0.1 \mathrm{~mL})$ was pipetted and transferred into a beaker with $10 \mathrm{~mL}$ of $0.25 \mathrm{~mol} \mathrm{~L}^{-1} \mathrm{H}_{2} \mathrm{SO}_{4}, 2.5 \mathrm{~mL}$ of 0.5 mol L ${ }^{-1}$ sodium tungstate and $2.5 \mathrm{~mL}$ of 1:2 phosphoric acid added successfully, and finally made up to $20 \mathrm{~mL}$ with distilled water. The solution was heated to boiling and allowed to cool until a yellow colour formed. This was poured into a $25 \mathrm{~mL}$ standard flask and made up to the mark, and the absorbance taken at $400 \mathrm{~nm}$ (Vogel, 1998). The electronic and infrared spectra were recorded on the Alpha spectrophotometer in the range $200-900 \mathrm{~nm}$ and the Buck scientific spectrophotometer in the range $4400-350 \mathrm{~cm}^{-1}$, respectively, at the Obafemi Awolowo University, Ile-Ife, Nigeria, and Ladoke Akintola University, Ogbomoso, Nigeria, in that order.

\section{Results and Discussion}

\subsection{The Effect of $\mathrm{pH}$}

The effect of $\mathrm{pH}$ on percentage $\mathrm{V}(\mathrm{V})$ extraction (E\%) from $\mathrm{HCl}$ solutions with 1-butanol and 1-octanol is presented in Figure 1. The $\mathrm{E} \%$ for $\mathrm{V}(\mathrm{V})$ extraction using 1-butanol was optimal at $\mathrm{pH} 0.5(\mathrm{E} \%=63.3)$ and was subsequently followed by an intermittent decrease/increase with the least value $(\mathrm{E} \%=13.3)$ observed at $\mathrm{pH}$ values of 2.5 and 3.0. This could be explained on the basis of prevalence of different extractable $\mathrm{V}(\mathrm{V})$ species at different $\mathrm{pH}$ regions, also unextractable hydrolysed species such as $\mathrm{H}_{2} \mathrm{~V}_{10} \mathrm{O}_{28}{ }^{4-}$ and $\mathrm{H}_{3} \mathrm{VO}_{4}$ have been observed (Greenwood \& Earnshaw, 1997).

This trend agrees with what some authors observed in $\mathrm{V}(\mathrm{V})$ extractions from aqueous acid solutions with organophosphorous extractants (Kurbatova \& Kurbatov, 2006; Ojo, 2010; J. Ojo, Adebayo, \& I. Ojo, 2012). As regards 1-octanol, it was found that at nearly all corresponding $\mathrm{pH}$ values, the $\mathrm{E} \%$ values for $\mathrm{V}(\mathrm{V})$ extraction was higher than 1-butanol, perhaps the greater lipophillic nature of the former was responsible, not surprisingly, substantial losses in volumes of 1-butanol to the aqueous phases were observed at high $\mathrm{pH}$ values, implying low hydrolytic stability. The $\mathrm{E} \%$ peaked at $\mathrm{pH}$ of $1.0(\mathrm{E} \%=73.3)$ and least at $\mathrm{pH} 4.0(\mathrm{E} \%=36.7)$.

Similarly, the gradual formation of unextractable hydrolysed species as the $\mathrm{pH}$ increased might be responsible for the decreased $\mathrm{E} \%$, after all, it is a known fact that a metal extracts best below the $\mathrm{pH}$ where it hydrolyses. The reactive extraction of $\mathrm{V}(\mathrm{V})$ by these alkanols at the studied $\mathrm{pH}$ range can generally be expressed by Equation (1).

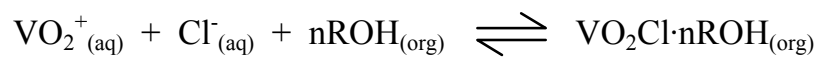

where "aq" and "org" represent the aqueous and organic phases respectively.

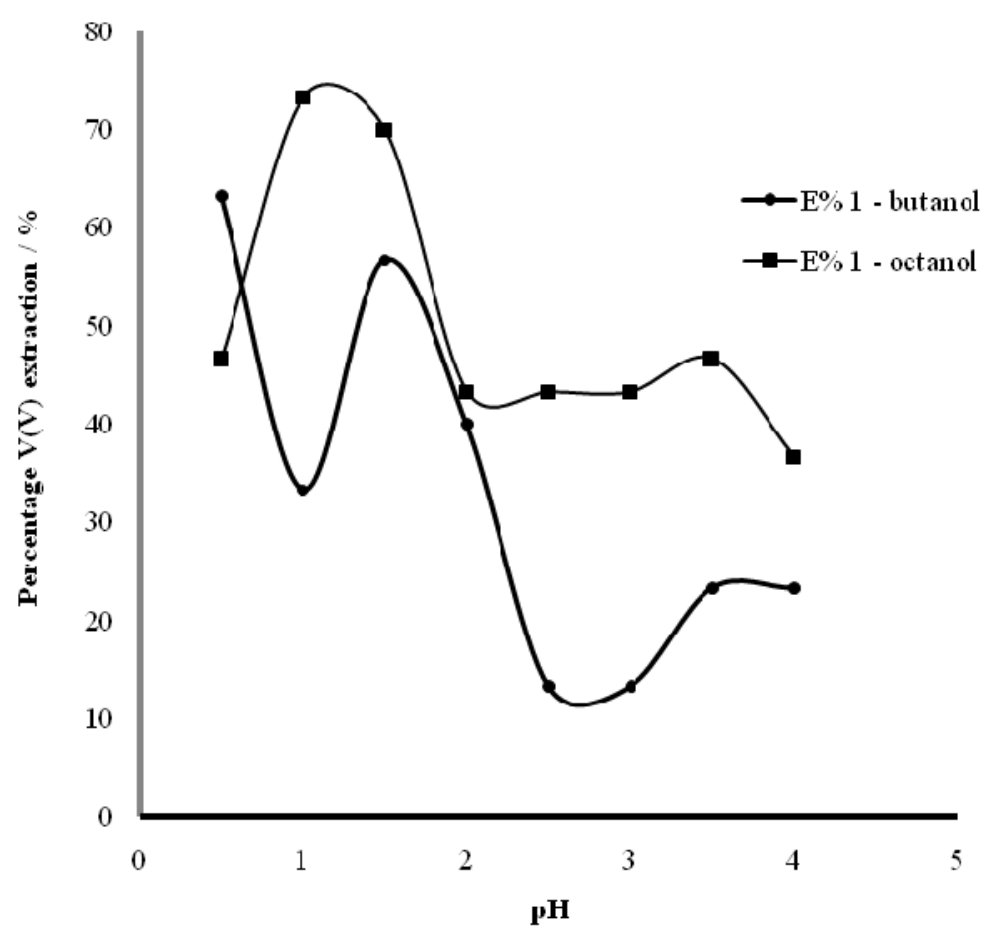

Figure 1. Effect of $\mathrm{pH}$ on percentage vanadium $(\mathrm{V})$ extraction with 1-butanol and 1-octanol $[\mathrm{V}(\mathrm{V})]=0.03 \mathrm{~mol} \mathrm{~L}^{-1}$; $[1$-butanol $]=7.61 \mathrm{~mol} \mathrm{~L}^{-1} ;[1$-octanol $]=4.32 \mathrm{~mol} \mathrm{~L}^{-1} ;$ Temperature $=301 \mathrm{~K}$ 


\subsection{Effect of Concentration of $\mathrm{HCl}$}

The effect of concentration of $\mathrm{HCl}$ at the studied range of $1.0-6.0 \mathrm{~mol} \mathrm{~L}^{-1}$ on vanadium (V) extraction with 1-butanol and 1-octannol is presented in Figure 2. With 1-butanol the $\mathrm{E} \%$ for $\mathrm{V}(\mathrm{V})$ extraction is of the trend increased, fairly constant and finally increased to an optimum value of $\mathrm{E} \%=86.7$ at $\mathrm{HCl}$ concentration of 6.0 $\mathrm{mol} \mathrm{L}^{-1}$. While for 1 octanol, E\% initially decreased followed by a continuous increase which reached an optimal value of $\mathrm{E} \%=70.0$ at the studied concentration range. This trend is similar to that observed in vanadium (V) extraction from hydrochloric acid solution by TBP (Thomas, Surrender, \& Reddy, 2003; Ojo \& Adeeyinwo, 2011).

The plausible explanation is probably the increased desolvation of the coordinated water molecules at higher acid concentration which renders the vanadium $(\mathrm{V})$ ion free for coordination by alkanol molecules, being neutral extractant.

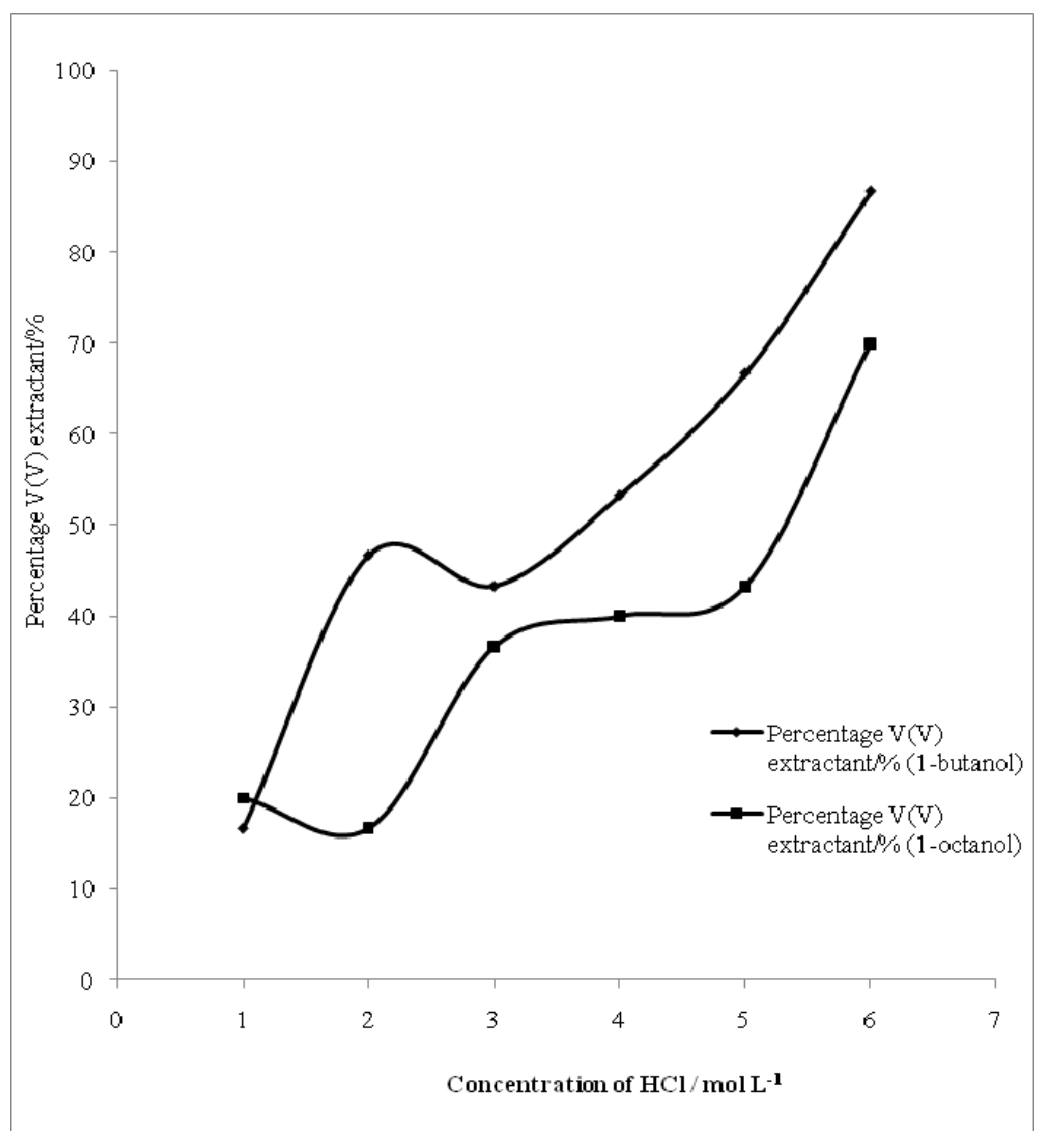

Figure 2. Effect of concentration of $\mathrm{HCl}$ solutions on percentage $\mathrm{V}(\mathrm{V})$ extraction. $[\mathrm{V}(\mathrm{V})]=0.03 \mathrm{~mol} \mathrm{~L}^{-1}$;

$[1$-butanol $]=7.61 \mathrm{~mol} \mathrm{~L}^{-1} ;[1$-octanol $]=4.32 \mathrm{~mol} \mathrm{~L}^{-1} ;$ Temperature $=301 \mathrm{~K}$

\subsection{Effect of Concentration of Extractants}

The effect of the concentration of 1-butanol and 1-octanol on vanadium (V) extraction is illustrated with Figures 3 and 4.

It was observed that 1-octanol exhibited a higher percentage extraction (E\%) than 1-butanol, and each of the extractants showed two almost linear portions on their curves.

At $\log [1$-butanol $]=0.81, \log \mathrm{D}=0.52(\mathrm{E} \%=76.7)$ which increased to an optimum of $\log \mathrm{D}=0.81(\mathrm{E} \%=86.7)$ at $\log [1$-butanol $]=0.88$ and subsequently decreased. With 1-octanol, at $\log [1$-octanol $]=0.27, \log \mathrm{D}=0.81(\mathrm{E} \%$ $=86.7)$ which increased to an optimum of $\log \mathrm{D}=1.46(\mathrm{E} \%=96.7)$ at an optimum of $\log [1$-octanol $]=0.49$ and decreased thereafter.

If $\mathrm{VO}_{2}{ }^{+}$is the predominant extractable species, its extraction by both alkanols can be generally represented by Equation 1. 
Then,

$$
\begin{gathered}
\mathrm{K}_{\mathrm{ex}}=\left[\mathrm{VO}_{2} \mathrm{Cl} \cdot \mathrm{nROH}\right]_{\mathrm{org}} /\left[\mathrm{VO}_{2}{ }^{+}\right]_{\mathrm{aq}} \cdot\left[\mathrm{Cl}^{-}\right]_{\mathrm{aq}} \cdot[\mathrm{ROH}]_{\mathrm{org}}{ }^{\mathrm{n}} \\
\mathrm{D}=\left[\mathrm{VO}_{2} \mathrm{Cl} \cdot \mathrm{nROH}\right]_{\mathrm{org}} /\left[\mathrm{VO}_{2}^{+}\right]_{\mathrm{aq}}
\end{gathered}
$$

Where "aq", "org”, $\mathrm{K}_{\mathrm{ex}}$ and $\mathrm{D}$ represent aqueous and organic phases, and extraction equilibrium constant and distribution coefficient, respectively.

Substituting, we have

$$
\mathrm{K}_{\mathrm{ex}}=\mathrm{D} /[\mathrm{ROH}]^{\mathrm{n}} \cdot\left[\mathrm{Cl}^{-}\right]
$$

Taking logarithm of both sides, while keeping $\left[\mathrm{Cl}^{-}\right]$constant, we have

$$
\log \mathrm{D}=\log \mathrm{Kex}+\mathrm{n} \cdot \log [\mathrm{ROH}]
$$

It is expected that a plot of $\log \mathrm{D}$ against $\log [\mathrm{ROH}]$ should yield a straight line of slope equal to ' $\mathrm{n}$ ' the number of solvated molecules. However, two linear portions were observed on the plots of both 1-butanol and 1-octanol at lower and higher extractant concentrations which implies that two different species were extracted at the varied conditions.

With 1-butanol, at the ascending portion of the curve (lower concentration), the determined slope, ' $n$ ' was equal to four and for the descending portion of the curve, it was -5.5 which implies that four molecules of 1-butanol were coordinated at lower concentration, while polymeric $\mathrm{V}(\mathrm{V})$ specie is coordinated to one molecule of 1-butanol, at high concentration, which is not supported by Equation (1).

As regards 1-octanol, the determined slope ' $n$ ' was equal to 5.0 and -3.2 at lower and higher extractant concentrations, respectively, implying that five molecules of 1-octanol were coordinated to $V(V)$ at lower concentrations while polymeric $\mathrm{V}(\mathrm{V})$ was coordinated to one molecule of 1-octanol at higher concentrations, similar to observations made in Mo (VI)/HCl/TBP system (Ojo et al., 2008) and these could not be rationalized by Equation (1).

The extraction at higher concentration of alkanols could therefore be represented by the Equation (6).

$$
\mathrm{mVO}_{2}^{+}+\mathrm{mCl}^{-}+\mathrm{nROH} \rightleftharpoons\left(\mathrm{VO}_{2} \mathrm{Cl}\right) \mathrm{m} \cdot \mathrm{nROH}
$$

which is of the limit $m>>n$. 




Figure 3. A plot of $\log \mathrm{D}$ versus $\log [1-$ butanol] for the extraction of $\mathrm{V}(\mathrm{V})$ from $\mathrm{HCl}$ solutions. $[\mathrm{V}(\mathrm{V})]=0.03$ $\mathrm{mol} \mathrm{L}-1,[\mathrm{HCl}]=6.0 \mathrm{~mol}^{-1} \mathrm{~L}^{-1} ;$ Temperature $=301 \mathrm{~K}$

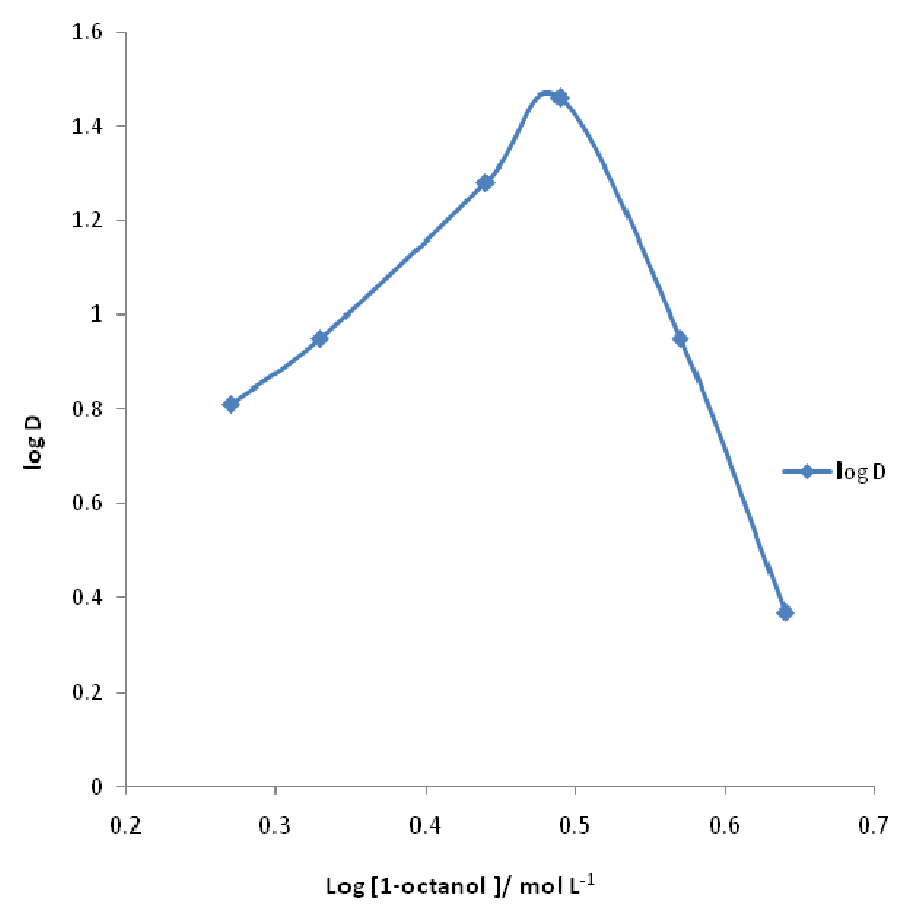

Figure 4. A plot of $\log \mathrm{D}$ versus $\log [1$-octanol] for the extraction of $\mathrm{V}(\mathrm{V})$ from $\mathrm{HCl}$ solutions. $[\mathrm{V}(\mathrm{V})]=0.03 \mathrm{~mol}$ $\mathrm{L}^{-1} ;[\mathrm{HCl}]=6.0 \mathrm{~mol}^{-1} \mathrm{~L}^{-1} ;$ Temperature $=301 \mathrm{~K}$ 


\subsection{Effect of Temperature}

The effect of temperature on the distribution coefficient of $\mathrm{V}(\mathrm{V})$ extraction from $6.0 \mathrm{~mol} \mathrm{~L}^{-1} \mathrm{HCl}$ by 1-butanol and 1-octanol at the temperature range $301-321 \mathrm{~K}$ is shown in Figures 5 and 6 . With 1-butanol, it was observed that the distribution coefficient decreased with increase in temperature. The Van't Hoff equation is

$$
\log \mathrm{D}=-\Delta \mathrm{H} / 2.303 \cdot \mathrm{RT}+\mathrm{C}
$$

where $\mathrm{D}, \Delta \mathrm{H}$ and $\mathrm{C}$ represent distribution coefficient, enthalpy change for the extractive reaction, respectively (Talla, Gaikward, \& Pawar, 2010). The plot of $\log \mathrm{D}$ against $1 / \mathrm{T} \times 1000$ yielded a straight line of the slope equal to 1.04 , and $\Delta \mathrm{H}$ was determined to be $-19.9 \mathrm{KJ} \mathrm{mol}^{-1}$ indicating an exothermic extractive reaction. This observation agrees with what was reported in tungsten (VI) extraction from $\mathrm{HCl}$ solutions with mixed trialky phosphine oxide (cyanex-923) (Talla, Gaikward, \& Pawar, 2010). As regards 1-octanol, the plot of logD versus $1 / \mathrm{T} \times 1000$ yielded a slope of 1.94 and $\Delta \mathrm{H}$ value of $-37.1 \mathrm{~kJ} \mathrm{~mol}^{-1}$. The extraction could similarly be referred to as exothermic.

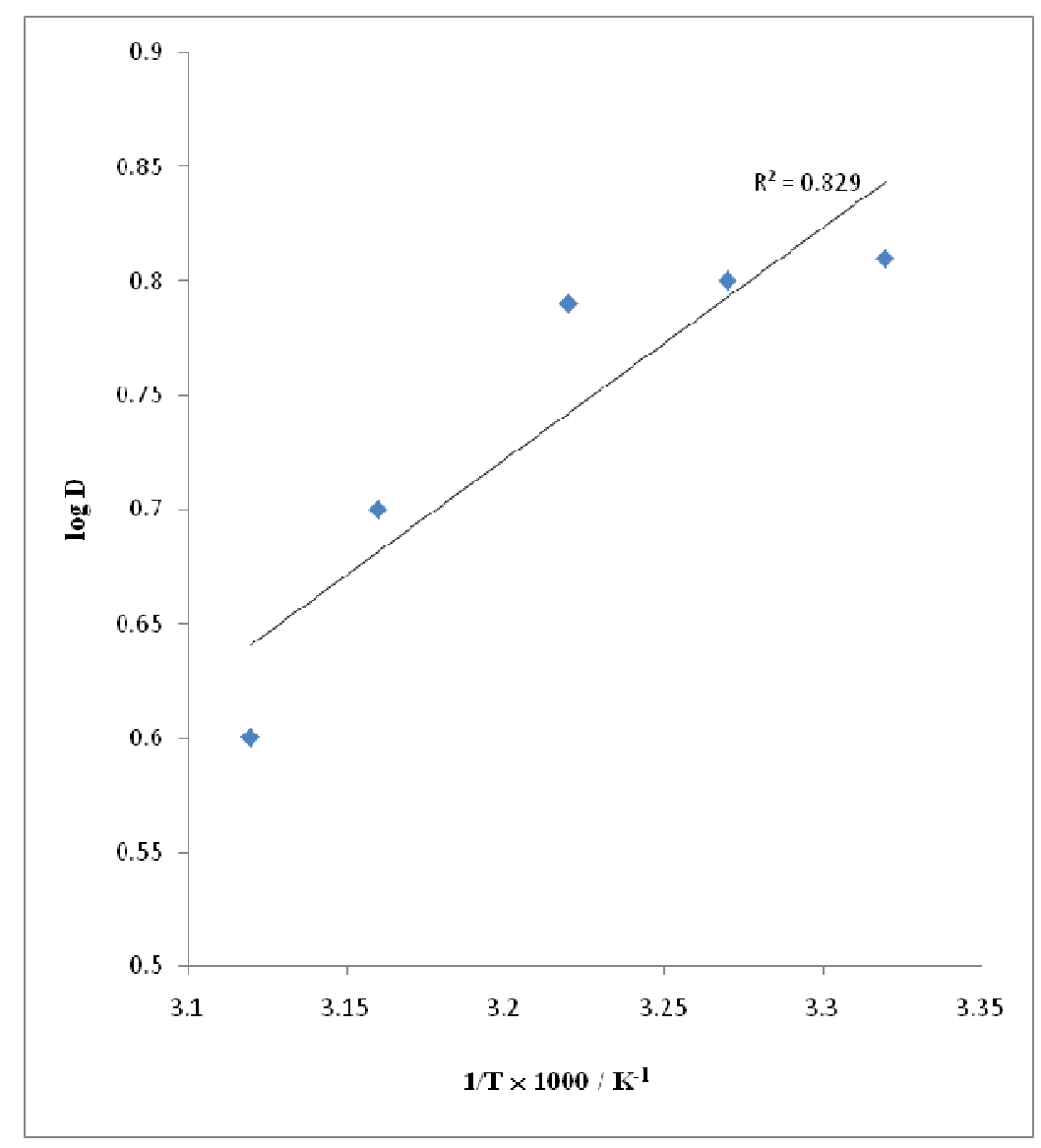

Figure 5. A plot of $\log \mathrm{D}$ versus $1 / \mathrm{T}$ x 1000 for the extraction of $\mathrm{V}(\mathrm{V})$ from $\mathrm{HCl}$ solutions with 1-butanol[V(V)] = $0.03 \mathrm{~mol} \mathrm{~L}^{-1} ;[\mathrm{HCl}]=6.0 \mathrm{molL}^{-1} ;[1$-butanol $]=7.61 \mathrm{~mol} \mathrm{~L}^{-1}$ 


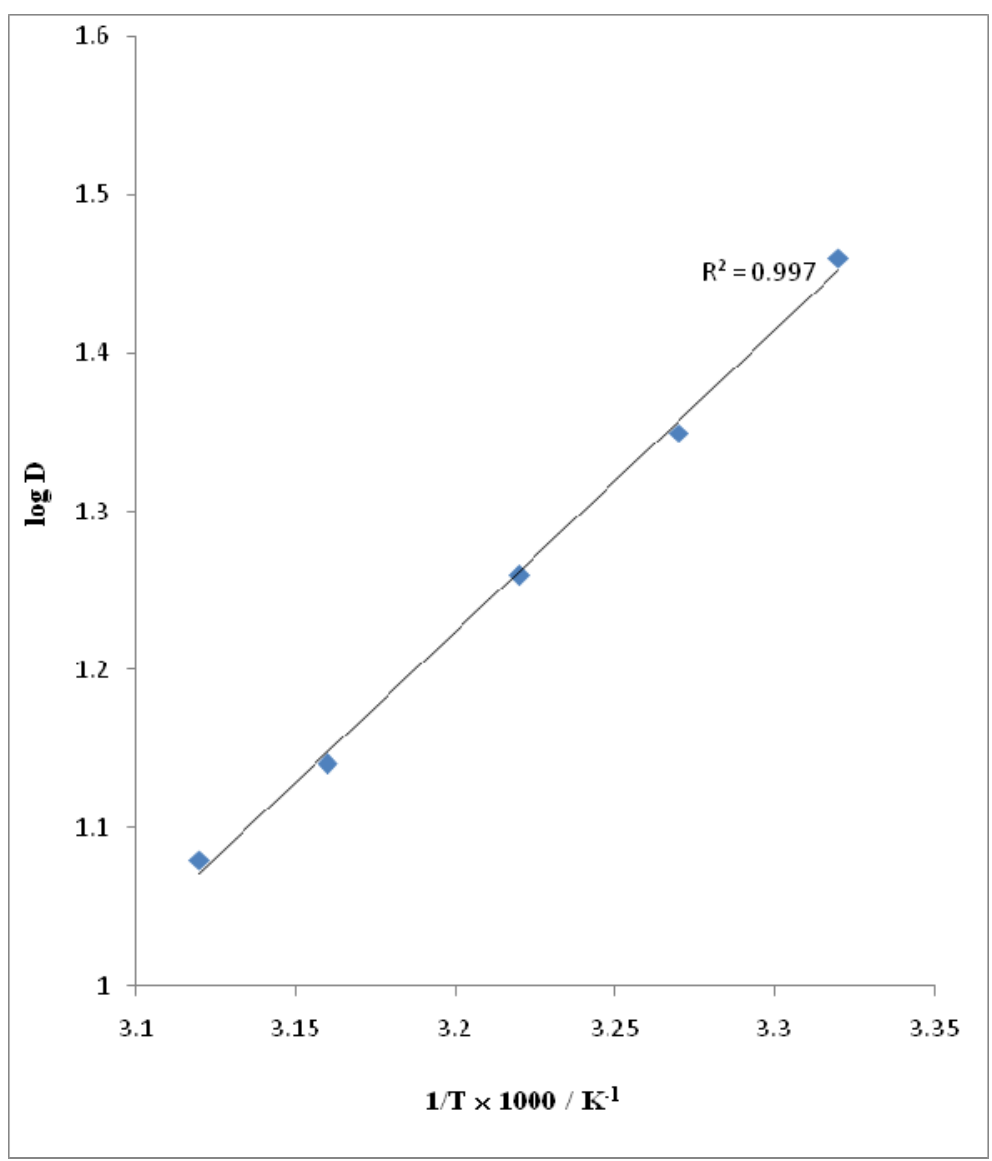

Figure 6. A plot of $\log \mathrm{D}$ versus $1 / \mathrm{T} \times 1000$ for the extraction of $\mathrm{V}(\mathrm{V})$ from $\mathrm{HCl}$ solutions with 1-octanol[V(V)] $=$ $0.03 \mathrm{~mol} \mathrm{~L}^{-1} ;[\mathrm{HCl}]=6.0 \mathrm{molL}^{-1} ;[1$-octanol $]=3.09 \mathrm{~mol} \mathrm{~L}^{-1}$

\subsection{Extraction Stages}

The determination of number of extraction stages required for a quantitative extraction of $\mathrm{V}(\mathrm{V})$ from $6.0 \mathrm{~mol} \mathrm{~L}^{-1}$ $\mathrm{HCl}$ by 1-butanool and 1-octanol is presented in Table 1. With the use of 1-butanol, the percentage of $\mathrm{V}(\mathrm{V})$ extracted after a consecutive three-stage of extraction was $88.6 \%$, while for 1 -octanol, it was $99.3 \%$ after the same number of extraction stages, making the later to be more efficient.

Table 1. The effect of number of extraction stages on percentage $V(V)$ extraction with 1-butanol and 1-octanol

\begin{tabular}{ccccc}
\hline Stage & \multicolumn{2}{c}{ 1-butanol } & \multicolumn{2}{c}{ 1-octanol } \\
\hline & $\mathbf{V}(\mathbf{V}) \mathbf{c o n c}^{\mathbf{a}} . /\left(\mathbf{g ~ L}^{\mathbf{- 1}}\right)$ & $\mathbf{E ~ ( \% )}$ & $\mathbf{V}(\mathbf{V}) \mathbf{c o n c}^{\mathbf{a}} . /\left(\mathbf{g ~ L ~}^{\mathbf{- 1}}\right)$ & $\mathbf{E ~ ( \% )}$ \\
\cline { 2 - 5 } 1 & 0.187 & 87.6 & 0.05 & 96.7 \\
2 & 0.181 & 88.1 & 0.037 & 97.6 \\
3 & 0.174 & 88.6 & 0.011 & 99.3 \\
\hline
\end{tabular}

Initial $\mathrm{V}(\mathrm{V})$ concentartion $=1.529 \mathrm{~g} \mathrm{~L}^{-1}$.

${ }^{\mathrm{a}}=[\mathrm{V}(\mathrm{V})]$ left in aqueous phase.

\subsection{Recycling}

The effect of the number of recycling stages of 1-butanol and 1-octanol on the distribution coefficient, percentage extraction and recycling coefficient of $\mathrm{V}(\mathrm{V})$ in $6.0 \mathrm{~mol} \mathrm{~L}^{-1} \mathrm{HCl}$ medium is presented in Table 2 . 
With 1-butanol, the distribution coefficient (D) and percentage extraction (E\%) decreased with three consecutive extractions from $\mathrm{E} \%=86.7$ (at $\mathrm{D}=6.5$ ) to 73.3 (at $\mathrm{D}=2.75$ ). In order to quantify the recycling effect, the recycling coefficient (R.C), was defined as "D" of initial extraction (or $1^{\text {st }}$ stage)/ "D" of $\mathrm{n}^{\text {th }}$ stage extraction (if R.C. $\geq 1.0$, the extractant is recyclable and if R.C. $<1.0$, it is weakly recyclable). The determined R.C. values were less than one using 1 - butanol. While for 1-octanol, the $\mathrm{E} \%=86.7$ (at D 6.45) was constant throughout and R.C. $=1.0$, hence, the extractant could be said to be recyclable which was supported by the in significant losses in volumes during equilibration unlike 1-butanol that showed great losses in volume.

Table 2. Effect of number of recycling stages on distribution coefficient, percentage extraction and recycling coefficient on $\mathrm{V}(\mathrm{V})$ extraction

\begin{tabular}{ccccccc}
\hline \multirow{2}{*}{ Recycling stage } & \multicolumn{3}{c}{ 1-butanol } & \multicolumn{3}{c}{ 1-octanol } \\
\cline { 2 - 7 } & D & E/\% & R.C $C^{\mathrm{b}}$ & $\mathrm{D}$ & $\mathrm{E} / \%$ & R.C \\
\hline $1^{\mathrm{c}}$ & 6.5 & 86.7 & - & 29.3 & 96.7 & - \\
2 & 5.0 & 83.3 & 0.8 & 31.3 & 96.9 & 1.0 \\
3 & 2.75 & 73.3 & 0.4 & 33.5 & 97.1 & 1.0 \\
\hline
\end{tabular}

$\mathrm{b}=$ recycling coefficient; $\mathrm{i}^{\mathrm{c}}=$ initial extraction

\subsection{Effect of Mixing of Extractants}

The effects of mixing of extractant with 1-butanol on $\mathrm{V}(\mathrm{V})$ extraction from $6.0 \mathrm{~mol} \mathrm{~L}^{-1} \mathrm{HCl}$ is depicted by Table 3 . All binary mixtures of the extractants in 1-butanol showed antagonistic behavior, more remarkable with the neutral extractants. The binary mixture of decanol and 1-butanol had the least percentage $\mathrm{V}(\mathrm{V})$ extraction of $\mathrm{E} \%=56.7$ compared with $\mathrm{E} \%=86.7$ when 1-butanol was used alone. It is not clear why the mixtures of solvating extractants could not produce an enhanced extraction, perhaps a decrease in solubility of the extracted complex in the binary mixture or deleterious interaction between 1-butanol and the extractant might be responsible as observed by some authors in D2EHPA extraction systems (J. Ojo, Adebayo, \& I. Ojo, 2012).

Table 3. Effect of mixing of extractants at a concentration of $10 \%(\mathrm{v} / \mathrm{v})$ with $7.61 \mathrm{~mol} \mathrm{~L}^{-1}(70 \% \mathrm{v} / \mathrm{v})$ 1-butanol on percentage $\mathrm{V}(\mathrm{V})$ extraction from $6.0 \mathrm{~mol} \mathrm{~L}^{-1} \mathrm{HCl}$

\begin{tabular}{cc}
\hline Extractant & $\mathbf{E} / \mathbf{\%}$ \\
\hline- & $86.7^{\mathrm{d}}$ \\
1-octanol & 70.0 \\
1-decanol & 56.7 \\
1-pentanol & 66.7 \\
Isopentyl alcohol & 70.0 \\
2-methyl propan-2-ol & 66.7 \\
Trioctylamine & 76.7 \\
D2EHPA & 70.0 \\
TBP & 63.3 \\
\hline
\end{tabular}

$\mathrm{d}=1$-butanol only.

\subsection{Effect of Added Foreign Ions}

The effect of added foreign ions on $\mathrm{V}(\mathrm{V})$ extraction from $6.0 \mathrm{~mol} \mathrm{~L}^{-1} \mathrm{HCl}$ with 1-butanol and 1-octanol is presented in Table 4. All the foreign ions added at a concentration of $0.0015 \mathrm{~mol} \mathrm{~L}^{-1}(5 \%$ of initial $[\mathrm{V}(\mathrm{V})])$ decreased the percentage $\mathrm{V}(\mathrm{V})$ extraction except $\mathrm{Co}(\mathrm{II})$ in the octanol/V(V) system. In the 1-butanol V(V) system, Mo (VI) was more tolerated than Co (II) since the percentage decrease (difference in $\mathrm{E} \%$ after added foreign ion / $\mathrm{E} \%$ without foreign ion $\mathrm{x} \mathrm{100)}$ was higher with the later. With 1-octanol, $\mathrm{Pb}(\mathrm{II})$ was the least tolerated, because it showed the highest percentage decrease in $\mathrm{E} \%$. 
This implies that the ions if present in real mixtures would be deleterious \{save Co(II)\} to V(V) removal from $\mathrm{HCl}$ solutions at the prevailing experimental conditions except if removed from the admixtures prior to $\mathrm{V}(\mathrm{V})$ extraction.

It appears that no clear-cut reason could be advanced for the differential behaviors, perhaps the extent of solubility of the metal admixtures could be responsible.

Table 4. The effect of added $0.015 \mathrm{~mol} \mathrm{~L}^{-1}$ foreign ions on percentage $\mathrm{V}(\mathrm{V})$ extraction from $6.0 \mathrm{~mol} \mathrm{~L}^{-1} \mathrm{HCl} \mathrm{with}$ 1-butanol and 1-octanol

\begin{tabular}{cccccc}
\hline \multirow{2}{*}{ Foreign ion } & \multirow{2}{*}{ Added as } & \multicolumn{2}{c}{ 1-butanol } & \multicolumn{2}{c}{ 1-octanol } \\
\cline { 3 - 6 } & & $\mathrm{E} / \%$ & $\%$ decrease & $\mathrm{E} / \%$ & $\%$ decrease \\
\hline- & - & $86.7^{\mathrm{e}}$ & - & $96.7^{\mathrm{f}}$ & - \\
$\mathrm{Mo}(\mathrm{VI})$ & $\mathrm{MoO}_{3}$ & 80.3 & 7.7 & 76.7 & 20.7 \\
$\mathrm{Co}$ (II) & $\mathrm{CoCl}_{2}$ & 73.3 & 15.5 & 96.7 & 0.0 \\
$\mathrm{Cu}(\mathrm{II})$ & $\mathrm{CuCl}_{2}$ & - & - & 90.0 & 6.9 \\
$\mathrm{~Pb}$ (II) & ${\mathrm{Pb}\left(\mathrm{NO}_{3}\right)_{2}}$ & - & - & 70.0 & 27.6 \\
$\mathrm{As}$ (II) & $\mathrm{As}_{2} \mathrm{O}_{3}$ & - & - & 90.0 & 6.9 \\
\hline
\end{tabular}

$\mathrm{e}, \mathrm{f}=\mathrm{E} \%$ without foreign ion with 1-butanol and 1-octanol, respectively [1-butanol] $=7.61 \mathrm{~mol} \mathrm{~L}{ }^{-1} ;[1$-octanol] $=$ $3.09 \mathrm{~mol} \mathrm{~L}^{-1}$.

\subsection{Electronic Spectra}

The electronic spectra bands of 1-butanol dissolved in n-heptane, aqueous and organic phases of 1-butanol-V(V) are presented in Table 5.

The electronic absorption spectra of 1-butanol in n-heptane showed absorption bands at $29070\left(\varepsilon<1.0 \mathrm{M}^{-1} \mathrm{~cm}^{-1}\right)$ ascribable to $n \rightarrow \sigma^{*}$ transition, which shifted positively (hypsochromic shift) by about 4487 and $3188 \mathrm{~cm}^{-1}$ in the aqueous and organic phases of 1-butanol-V(V) system suggesting a different electronic transition mechanism, most probably, ligand-to-metal charge transfer (LMCT) between the bound $\mathrm{Cl}^{-}$and $\mathrm{V}(\mathrm{V})$ lend credence to by the observed and typically high molar absorptivity $\left(\varepsilon=615-1813 \mathrm{M}^{-1} \mathrm{~cm}^{-1}\right)$. With the solution of 1-octanol in n-heptane, its absorption band was observed at $30120\left(\varepsilon<1.0 \mathrm{M}^{-1} \mathrm{~cm}^{-1}\right)$ ascribable to $\mathrm{n} \rightarrow \sigma^{*}$ transition. The hypsochromic shifts were about 3664 and $2138 \mathrm{~cm}^{-1}$ for the aqueous and organic phases of 1-butanol-V(V) system, respectively, and molar absorptivities were 3000 and $345 \mathrm{M}^{-1} \mathrm{~cm}^{-1}$ in that order, similarly, charge transfer could be fingered out (J. Ojo, Adebayo, \& I. Ojo, 2012; Ojo, 2013).

Table 5. Electronic spectra data for the extractants, aqueous and organic phases of V(V) in 1-butanol and 1-octanol

\begin{tabular}{cccc}
\hline Compound & Band $\left(\mathbf{c m}^{-\mathbf{1}}\right)$ & $\boldsymbol{\varepsilon} / \mathbf{~ M}^{-\mathbf{1}} \mathbf{c m}^{-\mathbf{1}}$ & Assignment \\
\hline 1-butanol solution & 29070 & $<1$ & $\mathrm{n} \rightarrow \sigma^{*}$ \\
Aqueous phase of $\mathrm{V}(\mathrm{V})$ & 33557 & 1813 & Charge transfer \\
Organic phase of V(V) & 32258 & 615 & Charge transfer \\
A-octanol & 30120 & $<1$ & Charge transfer \\
Aqueous phase of V(V) & 33784 & 3000 & Charge transfer \\
Organic phase of V(V) & 32258 & 345 & Charge transfer \\
\hline
\end{tabular}

\subsection{Infrared Spectra}

The infrared spectra data for the extractant and organic phases of 1-butanol-V(V) and 1-octanol-V(V) are presented in Table 6.

With 1-butanol extractant, infrared absorption bands are observed at 3410 and $2980 \mathrm{~cm}^{-1}$ ascribable to $v(\mathrm{O}-\mathrm{H})$ and $v(\mathrm{C}-\mathrm{H})$ vibration, respectively. 
In the organic phases, the $v(\mathrm{O}-\mathrm{H})$ vibration shifted downwards by $84 \mathrm{~cm}^{-1}$ indicating the involvement of the oxygen atom of the hydroxyl group in bonding to the $\mathrm{VO}_{2}{ }^{+}$ion.

A new band observed at $800 \mathrm{~cm}^{-1}$ assigned to $\mathrm{v}(\mathrm{V}=\mathrm{O})$ also serves as evidence of coordination of the pervanadyl ion $\left(\mathrm{VO}_{2}^{+}\right)$to the oxygen atom of the hydroxyl group.

As regards 1-octanol extractant, the observed bands are 3391 and $2990 \mathrm{~cm}^{-1}$ assigned to $v(\mathrm{O}-\mathrm{H})$ and $v(\mathrm{C}-\mathrm{H})$ vibrations. In the organic phase, the $v(\mathrm{O}-\mathrm{H})$ shifted downwards by $184 \mathrm{~cm}^{-1}$ indicating that the hydroxyl group was involved in bonding to the $\mathrm{VO}_{2}{ }^{+}$ion. In addition, a new band observed at $800 \mathrm{~cm}^{-1}$ which was absent in the extractant has been assigned to $v(\mathrm{~V}=\mathrm{O})$ which serves as a conclusive proof of coordination of the pervanadyl ion to the alkanolic hydroxyl group (Ojo, 2010; Kurbatova, Kurbatov, \& Medvedeva, 2004; Kurbatova \& Kurbatov, 2006; Lamber, Sharvell, Lightner, \& Cooks, 1987).

Table 6. Infrared spectra data for the extractant and organic phase of $V(V)$ in 1-butanol and 1-octanol

\begin{tabular}{ccc}
\hline Compound & Band $\left(\mathbf{c m}^{-1}\right)$ & Assignment \\
\hline \multirow{3}{*}{ 1-butanol solution } & 3410 & $v(\mathrm{O}-\mathrm{H})$ \\
& 2980 & $\mathrm{v}(\mathrm{C}-\mathrm{H})$ \\
\hline \multirow{3}{*}{ Organic phase of V(V) } & 3326 & $\mathrm{v}(\mathrm{O}-\mathrm{H})$ \\
& 2980 & $\mathrm{v}(\mathrm{C}-\mathrm{H})$ \\
& 800 & $\mathrm{v}(\mathrm{V}=\mathrm{O})$ \\
\hline \multirow{2}{*}{ 1-octanol solution } & 3301 & $\mathrm{v}(\mathrm{O}-\mathrm{H})$ \\
& 2990 & $\mathrm{v}(\mathrm{C}-\mathrm{H})$ \\
& 3207 & $\mathrm{v}(\mathrm{O}-\mathrm{H})$ \\
\hline & 2990 & $\mathrm{v}(\mathrm{C}-\mathrm{H})$ \\
Organic phase of V(V) & 800 & $\mathrm{v}(\mathrm{V}=\mathrm{O})$ \\
\hline
\end{tabular}

\section{Conclusion}

From the current study, it was adjudged that 1-octanol was a better extractant than 1-butanol for the extraction of $\mathrm{V}(\mathrm{V})$ from $\mathrm{HCl}$ solutions because it has a higher optimum extraction efficiency $(\mathrm{E} \%$ of 1 -octanol $=96.7, \mathrm{E} \%$ 1 -butanol $=86.7$ ) and more recyclable (R.C. of 1 -octanol $=1.0$, R.C. 1 -butanol $<1.0$ ) in terms of undiminished extraction efficiency as well as the noticed insignificant volume losses with repeated use. On this basis, it is recommended that 1-octanol should be selected as extractant ahead of 1-butanol for $\mathrm{V}(\mathrm{V}) / \mathrm{HCl}$ extraction system under the prevailing conditions.

\section{Acknowledgments}

The technical assistance of Mr. Akinola of the Central Laboratory, ObafemiAwolowo University, Ile-Ife, is well appreciated in the taking of some measurements.

\section{References}

Alibrahim, M., Shlewit, H., \& Alike, S. (2008). Solvent extraction of vanadium (IV) with di (2-ethylhexyl) phosphoric acid andtributyl phosphate. Chemical Engineering, 52, 29-33.

Bal, Y., Bal, K. E., Cote, G., \& Lallam, A. (2004). Characterization of the third phases that precipitate from the organic solutions of Aliquat 336 after extraction of molybdenum (VI) and vanadium (V). Hydrometallurgy, 75(1-4), 123-134. http://dx.doi.org/10.1016/j.hydromet.2004.07.004

El-Hazek, M. N., Amer, T. E., Abul El-Azm, M. G., Issa, R. M., \& El-Hady, S. M. (2012). Liquid-liquid extraction of tantalum and niobium by octanol from sulfate leachliquour. Arabian Journal of Chemistry, 5, 31-39. http://dx.doi.org/10.1016/j.arabjc.2010.07.020

El-Nadi, Y. A., Awwad, N. S., \& Nayl, A. A. (2009). A comparative study of vanadium extraction by Aliquat-336 from acidic and alkaline media with application to spent catalyst. International Journal of Mineral Processing, 92(3-4), 115-120. http://dx.doi.org/10.1016/j.minpro.2009.03.005 
Greenwood, N. N., \& Earnshaw, N. (1997). Chemistry of the Elements (2nd ed.). England: Pergamon Press Plc.

Huifang, C., Wannian, H., \& Yugi, Z. (1996). Separation of Ta and Nb by extraction with sec-octanol-HF- $\mathrm{H}_{2} \mathrm{SO}_{4}$ system. Transaction of Nonferrous Metallurgical Society of China, 6(3), 40-43.

Jain, V. K., \& Mandalia, H. C. (2009). Liquid-liquid extraction, separation, preconcentration and spectrophotometric determination of vanadium $(\mathrm{V})$ by tetra functionalized calix[4] pyrrolehydroxamic acid. Macroheterocycles, 2(1), 23-29.

Jain, V. K., Manadalia, H. C., \& Suresh, E. (2008). A facial microwave-assisted synthesis, spectroscopic characterization and preliminary complexation studies of Calix [4] pyrroles containing the hydroxamic-acid moiety. Journal of Inclusion Phenomena and Macrocyclic Chemistry, 62(1-2), 167-178. http://dx.doi.org/10.1007/s10847-008-9453-1

Kurbatova, L. D., \& Kurbatov, D. I. (2006). Extraction recovery of vanadium (V) from sulphuric acid solutions. Russian Journal of Applied Chemistry, 79, 850-852. http://dx.doi.org/10.1134/S1070427206050302

Kurbatova, L. D., Kurbatov, D. I., \& Medvedeva, N. I. (2004). Mechanism of the extraction of vanadium (V) from sulphuric acid solutions with di (2-ethylhexyl) phosphoric acid. Russian Journal of Applied Chemistry, 77, 676-679. http://dx.doi.org/10.1023/B:RJAC.0000038692.79239.19

Lambert, J. B., Sharvell, H. F., Lightner, D. A., \& Cooks, R. G. (1987). Introduction to organic spectroscopy. New York: Macmillian Publishing Company.

Ojo, J. O. (2010). Solvent extraction of vanadium (V) from nitric acid solutions with di (2-ethylhexyl) phosphoric acid and tri-n-butyl phosphate. Malaysian Journal of Chemistry, 12(1), 175-183.

Ojo, J. O. (2013). Separation of simulated mixed $\mathrm{Mo}(\mathrm{VI})$ and $\mathrm{V}(\mathrm{V})$ from $\mathrm{HNO}_{3}$ and $\mathrm{HCl}$ solutions by selective extraction and stripping with tri-n-butyl phosphate as extractant. Separation Science and Technology, 48 (10), 1577-1584. http://dx.doi.org/10.1080/01496395.2012.745.154

Ojo, J. O., \& Adeeyinwo, C. E. (2011). Dependence of vanadium recovery on oxidation state in its solvent extraction from hydrochloric acid solutions with tri-n-butyl phosphate. Ife Journal of Science, 31(1), 175-184.

Ojo, J. O., Adebayo, A. O., \& Ojo, I. O. (2012). Comparative study of the extraction of V(V) and V(IV) from hydrochloric acid solutions with di(2-ethylhexyl) phosphoric acid. Ife Journal of Science, 14(1), 15-22.

Ojo, J. O., Ipinmoroti, K. O., \& Adeeyinwo, C. E. (2007). Kinetics and mechanisms of V(V) extraction from hydrochloric acid solutions with tri-n-butyl phosphate. Journal of Chemical Society of Nigeria, 32(2), 166-173.

Ojo, J. O., Ipinmoroti, K. O., \& Adeeyinwo, C. E. (2008). Solvent extraction of molybdenum (VI) from diluted and concentrated hydrochloric acid solutions with tri-n-butyl phosphate. Global Journal of Pure and Applied Sciences, 14(3), 289-294. http://dx.doi.org/10.4314/gjpas.v14i3.16810

Talla, B. G., Gaikwad, S. U., \& Pawar, S. D. (2010). Solvent extraction separation of Mo(VI) and W(VI) from hydrochloric acid solutions using cyanex-923 as extractant. Indian Journal of Chemical Technology, 17, 436-440.

Thomas, J., Surender, G. D., \& Reddy, M. L. P. (2003). Solvent extraction separation of vanadium (V) from multimetal chloride solutions using tributylphosphate.Separation Science and Technology, 38(15), 3761-3774. http://dx.doi.org/10.1081/SS-120024228

Vogel, A. I. (1998). Vogel's Textbook of Quantitative Inorganic Analysis (5th ed.). Essex: Longman Group Limited.

Yamada, H., Hayashi, H., \& Yasui, T. (2006). Utility of 1-octanol/octane mixed solvents for the solvent extraction of Aluminium (III), Gallium (III), and Indium (III) with 8-Quinolinol. Analytical Sciences, 22, 371-376. http://dx.doi.org/10.2116/analsci.22.371

\section{Copyrights}

Copyright for this article is retained by the author(s), with first publication rights granted to the journal.

This is an open-access article distributed under the terms and conditions of the Creative Commons Attribution license (http://creativecommons.org/licenses/by/3.0/). 